OPEN ACCESS

Edited by:

Leonardo Neves de Andrade, University of São Paulo, Brazil

Reviewed by: Mohammad Farahpour, Islamic Azad University of Urmia, Iran Mark Wainwright, Liverpool John Moores University, United Kingdom

*Correspondence: Montserrat Pérez perezpineromontse@hotmail.com

tThese authors have contributed equally to this work

Specialty section: This article was submitted to Infectious Diseases - Surveillance, Prevention and Treatment, a section of the journal Frontiers in Medicine

Received: 27 February 2021 Accepted: 28 April 2021 Published: 25 May 2021

Citation:

Pérez $M$, Robres $P$, Moreno $B$ Bolea $R$, Verde MT, Pérez-Laguna $V$, Aspiroz C, Gilaberte $Y$ and Rezusta $A$

(2021) Comparison of Antibacterial

Activity and Wound Healing in a Superficial Abrasion Mouse Model of Staphylococcus aureus Skin Infection Using Photodynamic Therapy Based on Methylene Blue or Mupirocin or

Both. Front. Med. 8:673408. doi: 10.3389/fmed.2021.673408

\section{Comparison of Antibacterial Activity and Wound Healing in a Superficial Abrasion Mouse Model of Staphylococcus aureus Skin Infection Using Photodynamic Therapy Based on Methylene Blue or Mupirocin or Both}

\author{
Montserrat Pérez ${ }^{1 *}$, Pilar Robres ${ }^{2}$, Bernardino Moreno ${ }^{1}$, Rosa Bolea ${ }^{1}$, Maria T. Verde ${ }^{1}$, \\ Vanesa Pérez-Laguna ${ }^{3}$, Carmen Aspiroz ${ }^{4}$, Yolanda Gilaberte ${ }^{5+}$ and Antonio Rezusta ${ }^{3+}$ \\ ${ }^{1}$ Animal Pathology Department, Veterinary Faculty, Zaragoza University, Zaragoza, Spain, ${ }^{2}$ Department of Microbiology, \\ Hospital de Barbastro, Huesca, Spain, ${ }^{3}$ Department of Microbiology, Hospital Universitario Miguel Servet, IIS Aragón, \\ Zaragoza, Spain, ${ }^{4}$ Department of Microbiology, Hospital Royo Villanova, IIS Aragón, Zaragoza, Spain, ${ }^{5}$ Department of \\ Dermatology, Hospital Universitario Miguel Servet, IIS Aragón, Zaragoza, Spain
}

Background: Antibiotic resistance and impaired wound healing are major concerns in S. aureus superficial skin infections, and new therapies are needed. Antimicrobial photodynamic therapy (aPDT) is a new therapeutic approach for infections, but it also improves healing in many wound models.

Objective: To compare the antimicrobial activity and the effects on wound healing of aPDT based on Methylene Blue (MB-aPDT) with mupirocin treatment, either alone or in combination, in superficial skin wounds of $S$. aureus-infected mice. Additionally, to evaluate the clinical, microbiological, and cosmetic effects on wound healing.

Materials and Methods: A superficial skin infection model of $S$. aureus was established in $\mathrm{SKH}-1$ mice. Infected wounds were treated with MB-aPDT, MB-aPDT with a daily topical mupirocin or only with mupirocin. No treatment was carried out in control animals. Daily clinical and microbiological examinations were performed until complete clinical wound healing. Histopathological studies and statistical analysis were performed at the end of the study.

Results: MB-aPDT treatment induced the best wound healing compared to mupirocin alone or to mupirocin plus MB-aPDT. Superficial contraction at $24 \mathrm{~h}$ and a greater reduction in size at $48 \mathrm{~h}$, quicker detachment of the crust, less scaling, and absence of scars were observed. Histopathological studies correlated with clinical and gross findings. By contrast, mupirocin showed the highest logaritmic reduction of $S$. aureus.

Conclusions: MB-aPDT and mupirocin treatments are effective in a murine superficial skin infection model of $S$. aureus. One session of MB-aPDT was the best option for 
clinical wound healing and cosmetic results. The addition of mupirocin to MB-aPDT treatment improved antimicrobial activity; however, it did not enhance wound healing. No synergistic antibacterial effects were detected.

Keywords: $S$ aureus, SKH-1 mice, superficial wound infection, wound healing, photoinactivation, mupirocin, antimicrobial

\section{RESUME}

Antimicrobial photodynamic therapy based on Methylene Blue (MB-aPDT) is recognized for wound healing and microbial properties. To compare in vivo efficacy of MB-aPDT vs. mupirocin (MU), we utilized a murine superficial abrasive wound model to study bacterial count, wound healing and cosmetics results. Mice were wounded dorsally and infected with Staphylococcus aureus (ATCC 29213 strain). Experimentally infected wound was treated topically either with MB-aPDT, MU, $\mathrm{MB}-\mathrm{aPDT}+\mathrm{MU}$, or left untreated (control). Topically wounds were daily monitored (bacterial burden and wound healing) until clinical resolution. All mice develop purulent wounds as result of infection. Clinical evolution, gross observations, and histopathological findings are representative of acute infection, dermal response and histopathological hyperkeratosis at the clinical cure in animal model and antimicrobial trial. We demonstrated benefits of treatment in relation to control wounds. This study suggests that both treatments are significantly effective: MB-aPDT improves quick mild wound contraction at $24 \mathrm{~h}$, better wound healing (reduction of size, crust loss) and cosmetics results (no scar). MU enhances antimicrobial activity which seems not to be relevant for wound healing. Best clinical healing was observed in wounds treated with MB-aPDT but further studies were warranted to test the effectiveness of more sessions of MB-aPDT to enhance microbicide formulation of aPDT, alone or in combination with antibiotics. No antimicrobial synergistic effect was observed in this self-limiting infection model. Further experiments may be a suitable choice.

\section{INTRODUCTION}

Staphylococcus spp. causes $90 \%$ of torpid wound healing skin infection (1). Staphylococcus aureus is present in $60 \%$ of the biofilms of chronic wounds $(2,3)$, in the skin of $90 \%$ atopic patients (4) and it causes $75 \%$ of primary human pyoderma (5). Moreover, it is highlighted that one fifth of skin and soft tissue infections patients that received antibiotics develop recurrent skin infection with the same strain of $S$. aureus, developing resistance and increase of the dose of antimicrobials needed (68). Regarding mice, $S$. aureus is ubiquitous in the digestive and nasal mucosa and causes purulent dermatoses (9); additionally, in skin infection model, it mimics human disease (10) with suppurative dermatitis and abscesses $(11)$ in mice SKH-1 $(12,13)$.

In this context, murine infection $S$. aureus models are recommended for in vivo development of new antimicrobials. Different types of incisions (scalpel, punch), tape stripping o burning procedures promotes skin sensibility to diverse types of bacteria, although $S$. aureus is able to cause infection even in intact skin (14). There is not an ideal model and it is desirable to select the best choice for each purpose (15). Cutaneous procedures are easily in hairless mice and histopathology has typical features that reproduces cutaneous responses of humans $(16,17)$. On the other hand, skin contraction mainly in full thickness wound model is problematic (18) and wound healing in superficial model was developed by re-epithelization instead of tissue granulation (19). A superficial S. aureus infection model, better using abrasion that tape stripping, have difficulties due to self-limiting course and quick resolution in maximum 8 days (20). This model requires high bacterial load to infect the wound bed and social isolation of mice previous acclimation, however, it has been validated to evaluate topical antimicrobial therapies (21, 22). SKH-1 hairless mice have been validated for dermatological studies and it is recommended for wound healing studies (23).

According to guidelines, mupirocin (MU) is one of the main topical treatments for $S$. aureus skin infections and also in risk of developing resistances $(24,25)$. On the other hand, facing the problem of antimicrobial resistance, one of the biggest challenges in medicine is to find alternative therapeutic treatments (8). Antimicrobial photodynamic therapy (aPDT) is a promising treatment for skin and mucosal infections whose mechanism of action is effective regardless of the antimicrobial resistance pattern (26). It is based on photosensitizer molecules with the propriety of being activated by visible light and react with oxygen generating reactive oxygen species, toxic to target cells (27). aPDT based on Methylene Blue (MB, MB-aPDT), the principal photosensitizer of the phenothiazine family, is a low-cost and easy-to-use technique that has already shown its antimicrobial applications in periodontal disease, impetigo or the exacerbation of human atopic dermatitis and the treatment cutaneous mycoses, leishmaniasis, and infected wounds (27-31) used in animals (32) and skin S. aureus murine models (33-35).

Among the drawbacks of aPDT, the main concern is the possibility of microbial regrowth after aPDT. Multiple sessions of aPDT or the combination of aPDT with topical antibiotic may avoid bacterial regrowth after it (even at $24 \mathrm{~h})(20,36-38)$.

Our group demonstrated the synergistic bactericidal effect of the combination of MB-aPDT with the antibiotics gentamicin, linezolid, or MU against in vitro S. aureus being the combination with the latter the most promising to transfer to the clinic $(39,74)$. However, in vitro results frequently overestimate in vivo findings (40). Factors of animal model such as individual microbiome or virulence are determinants $(41,42)$.

Here, this in vivo study compares the antimicrobial efficacy and skin regenerative effects (wound healing and cosmetics results) of MB-aPDT, topical MU or their combination in wounds infected with S. aureus of SKH-1 mice. Additionally, we optimize a superficial model of skin $S$. aureus infection in terms of 
macroscopic (gross aspects) and cosmetic result, histological findings, besides microbial counts for a therapeutical challenge.

\section{MATERIALS AND METHODS}

\section{Animals}

SKH-1 hairless mice were obtained from the Charles River Laboratories (Germany). All mice were 6-8-week-old females and were individually kept in cages for a few days prior to the experiment to acclimate and throughout the experiment to prevent wound damage. Cages were placed close to the ground for mice to acclimate to low light levels and mice were provided with commercial feed and water ad libitum. All procedures were carried out in biosafety chambers (LAF, Laminar Air Flow) for type 2 pathogens, located at the Centro de Investigación Biomédica de Aragón (CIBA, Zaragoza, Spain). Mice were anesthetized by inhalation with $2 \%$ isofluorane.

All experimental procedures performed with animals were approved by the Ethic Committee for Animal Experiments from the University of Zaragoza (PI40/13).

\section{Bacterial Strains}

Methicillin-sensible S. aureus ATCC 29213 strain was obtained from the American Type Culture Collection (ATCC, Rockville, $\mathrm{MD}$, USA). Bacteria were grown aerobically overnight on blood agar plates at $35^{\circ} \mathrm{C}$ and the inoculum was prepared following the standard procedures at the Microbiology Department of the Zaragoza Medical School. The inoculum was prepared adding colonies in distilled water (Gibco ${ }^{\circledR}$, Thermofisher, Spain) and adjusted to $0.50 \pm 0.03$ on the McFarland scale. A final concentration of $3 \times 10^{8} \mathrm{CFU} / \mathrm{mL}$ was obtained.

\section{Superficial Skin Infection and Microbiological Evaluation}

The in vivo model infection was colonization incisional by abrasion $(20,34)$ with a dose infective $(3 \times 108$ colony forming units $(\mathrm{CFU}) / \mathrm{mL}$ ) growing from 4 first hours in a self-limiting pattern (14) with bacterial maturation (105 CFU/mL) in $48 \mathrm{~h}$ post-inoculation and clinical duration of 10-12 days.

Two superficial abrasions were made in 20 mice under general anesthesia (dexmedetomidin/Ketamine IP $(1 \mathrm{mg} / \mathrm{kg}+75$ $\mathrm{mg} / \mathrm{kg}$, Dexdomitor ${ }^{\circledR} 0.1 \mathrm{mg} / \mathrm{mL}+$ Imalgene $^{\circledR} 50 \mathrm{mg} / \mathrm{mL}$ ) mice $(n=20)$. Skin was disinfected with $70 \%$ alcohol and abrasions were carried out with a scalpel $\left(n^{\circ} 11\right)$ until redness appeared and epidermis apparently was lost (Figure 1A). Wounds were $\sim 0.6 \mathrm{~cm}$ in diameter and were located in the dorsal area and at a distance of $1 \mathrm{~cm}$. Wounds were infected with the inoculum previously obtained and protected with a transparent sticking plaster (Omnifilm ${ }^{\circledR}$, Hartmann) for $24 \mathrm{~h}$. Mice were euthanized with $\mathrm{CO}_{2}$ when wounds were healed and skin biopsies were taken. To minimize the number of animals used in the experiment, each mouse has a wound used as its own control (43).

To determine the bacterial burden of the wounds throughout the experiment, swabs (DeltaSwab Amies ${ }^{\circledR}$, DeltaLab, Spain) were taken daily. To avoid contamination, swabs were taken prior to any procedure. Samples were studied using routine microbiological procedures. They were plated on sheep blood agar (no selective) and CNS agar (selective for coagulase negative staphylococci) and the number of bacteria quantified by serial dilution in phosphate buffered saline (PBS) buffer and expressed as $\mathrm{CFU} / \mathrm{mL}$ and $\log _{10}$. The threshold value for an established skin infection by $S$. aureus was $10^{5} \mathrm{CFU} / \mathrm{mL}$. All experiments were carried out 3-5 times. A reduction in the number of $\mathrm{CFU} / \mathrm{ml}$ of 6 $\log _{10}$ was considered indicative of bactericidal activity (74).

\section{Therapy Protocols}

Methylene Blue MB-aPDT treatment protocol on S. aureus infected skin had been compared with treatments based on Mupirocin, either alone (MU) or in combination (MB-aPDT + MU).

In order to perform the tests, a total of 14 mice received wounds and were infected with $S$. aureus. Wounds were treated with the different protocols. Figure 2 shows the test distribution. As per control, some wounds infected were left untreated whilst some wounds were left uninfected.

Out of the 16 mice, 12 received 2 wounds whilst the remaining 4 mice received 3 wounds. By sampling in this way, we ensured that each mouse would act as control for its own treatments. Each mouse had two wounds infected excluding control (untreated) and healthy groups with three wounds for comparison purposes.

Since each of the 14 mice had two infected wounds, the testing was carried out comparing two treatment protocols until clinical resolution at each mouse. All possible combinations were tested: MB-aPDT and MU, MB-aPDT and MB-aPDT+MU, MBaPDT and untreated, MB-aPDT+MU and MU, MB-aPDT and untreated, MU and untreated.

In total, 36 wounds were performed, out of which 12 received MB-aPDT treatment, 6 received MU treatment, 6 received a combination (MB-aPDT+MU), 6 were left untreated and 6 were not infected (Figure 2).

MB-aPDT treatment consisted of light irradiation of the infected wounds after sensitization with MB (Sigma-Aldrich ${ }^{\circledR}$ Corp., St. Louis, USA; Powder $\geq 82 \%$; Absorption at 620 $700 \mathrm{~nm}) . \mathrm{MB}$ was prepared in the dark just before use as previously reported $(32,74)$. Stock MB solution was prepared and diluted in bidistilled water to the desired concentration. Two drops of MB were deposited on the infected wounds and wounds were covered with a sticking plaster (Omnifilm ${ }^{\circledR}$, Hartman) until complete reabsorption. Irradiation was started after 30 min of incubation in darkness (Figure 1C) (40). Under inhalated anesthesia, each wound was illumined with a light emitted diode (LED) lamp (Aktilite ${ }^{\circledR}$, Photocure ASA, Oslo, Norway; fluence $74 \mathrm{~J} / \mathrm{cm}^{2}, 635 \mathrm{~nm}$ ) for $16 \mathrm{~min}$, at a distance of $6-8 \mathrm{~cm}$ (Figure 1D). A transient mild erythema was observed after irradiation.

MU treatment consisted on a daily application of $\sim 0.1 \mathrm{~mL}$ of MU ointment (Mupirocin Isdin ${ }^{\circledR} 20 \mathrm{mg} / \mathrm{gr}$, Barcelona, Spain) to the wound. An individual swap was used for each application and a gentle massage was applied until complete absorption of the ointment.

Combined treatment with MB-aPDT and MU consisted of a daily MU treatment applied, as previously described, started $24 \mathrm{~h}$ after the light irradiation of the MB-aPDT. 

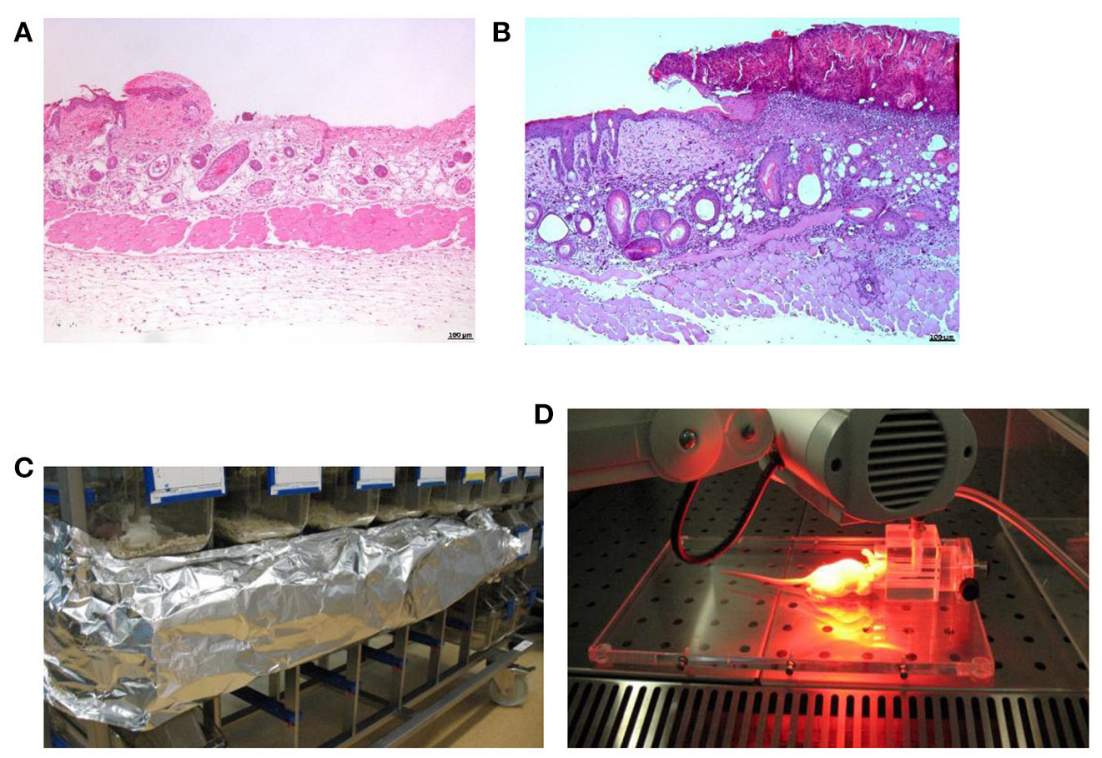

E

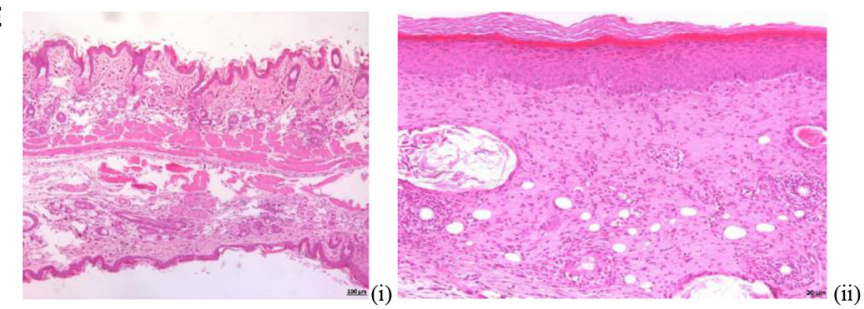

FIGURE 1 | Procedures in SKH-1 mice. (A) Microphotograph of skin abrasion experimentally induced. Note the very superficial loss of the epidermis. H-E. x50. (B) Microphotograph of the purulent crust observed at 24-48 h post-infection. H-E. x50. (C) Incubation of BM (aPDT) on dark. (D) MBa-PDT session. (E) Microphotograph of SKH-1 mice healthy skin (i) vs. skin healed per se (S. aureus infection) at 13 days post-inoculation (ii). H-E. x50.

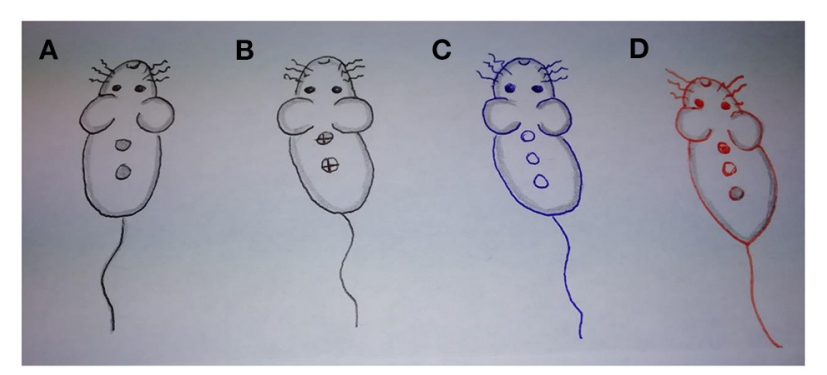

FIGURE 2 | Sampling of murine wounds (handmade) for comparisons. (A). Infected wounds treated with MB-aPDT. (B) Infected wounds treated with MU (dorsally combined with aPDT and ventrally in solitary). (C) Control (untreated) Infected wounds. (D) Healthy skin (dorsally ulcer by abrasion, in the middle intact skin, ventrally intact skin with $M B)$.

\section{Clinical Observations}

Mice were monitored daily to assess health (mental and physical status) in response to the infection and the different therapies.
Pathological characteristics of the wounds were assessed by the same investigator. The progression of the wound, estimating the days to get a reduction of $50 \%$ of size and the loss (detachment) of the crust (LC, time in days required to fall off) were evaluated. Additionally, gross lesions such as erythema and the presence of suppurative exudate, desquamation, contraction of the wounds and scars was also considered. Erythema and scaling were evaluated with visual skin-response scoring system as follows: 0 No observable effect; (1) Mild erythema; (2) Moderate erythema; (3) Strong erythema; (4) Dry desquamation; (5) Thin scab formation; (6) Thick scab formation (44). Digital images (Canon PowerShot A630() ) and a caliper were utilized for quantitative assessment of wound lesions.

\section{Histopathological Studies}

Biopsies were obtained by full-thickness excision of the skin at the time points of $24,48,76$, and $96 \mathrm{~h}$ post-infection, and at the end of the experiment, when clinical healing was observed. Additionally, a sample of healthy skin was taken from each mouse to use as control. Samples were fixed in $10 \%$ phosphate buffered formalin 
solution and routinely processed. Briefly, tissues were embedded in paraffin, sectioned at $4 \mu \mathrm{m}$, stained with hematoxylin and eosin, and microscopically studied with a Nikon microscope (Axioskop 40). Photographs were taken with a camera (AxioCam MRa5) and morphometric analyses were performed with the AXIOVision Rel.5.6 software.

The assessment of the epidermal thickness is not very difficult to perform with routine stains because its border with dermis is sharp. On the other hand, dermis study was made by measuring up to the panniculus carnosus muscle. Although this includes the hypodermis that was severely affected by the inflammation induced by the experimental injury and differentiation between dermis and hypodermis was often not very clear. Immunohistochemistry staining that has allowed a much better assessment of the dermis, unfortunately, we were unable to perform.

Skin biopsies were studied in a blind fashion, without knowing the different treatments. Initially, the thickness of the epidermis and dermis were estimated. At the epidermis, the main lesions studied were the presence and thickness of hyperkeratosis (ortho-keratotic or parakeratotic), crusts and rete ridges. In the dermis, the severity of fibroplasia, with estimation of the density of fibrocytes and fibroblasts, follicular lesions (with special attention to granulomatous folliculitis due to its normal presence in this kind of mouse), dermatitis (superficial or deep) and panniculitis were studied. The increase in conjunctive tissue, the cellularity, the rete ridge and the follicular cyst size and number were evaluated in a semiquantitative way establishing four categories: absent, mild, moderate, and severe.

\section{Statistical Analysis}

All statistical analysis were performed with the SPSS software v.22 (IBM Corp., Armonk, NY, USA). Kolmogorov-Smirnov test was performed to assess of normality of data. Qualitative changes were evaluated by Chi Square and Cramer's V (significance V $>0.3$ ). For non-parametric data, the Man-Withney or KruskalWallys test was used to detect significant differences between groups $(p<0.001)$. Normal data were compared with no paired Student $t$ or ANOVA test. Scheffe test was used for multiple comparison data post-hoc. $P<0.05$ was considered as significant.

\section{RESULTS}

\section{Development of a Mouse Model of Skin Infection (Abrasive Wound Infection Model)}

Clinical evaluation, gross, and histopathological examinations, and determination of the bacterial burden in the wound demonstrated that $S$. aureus grew within the following $48 \mathrm{~h}$ post-inoculation reaching its maximum at this time point, when the bacterial count was $\geq 10^{5} \mathrm{CFU} / \mathrm{mL}$ and the natural healing occurred at 10-12 days. Clinical lesions resembled impetigo and were characterized by erythema, edema, and purulent exudate at $24 \mathrm{~h}$ post-infection (Figure 3 ). Large purulent crusts developed and corresponded with the peaking of bacterial burden at $48 \mathrm{~h}$ (Figure 1B). Wound contraction started by $72 \mathrm{~h}$ post-inoculation histologically corresponding with presence of epidermal micro-abscesses. At $96 \mathrm{~h}$ post-infection, macroscopic and microscopic hyperkeratosis were extensive. At 10-12 days post-infection natural clinical recovery was observed presenting equally skin hyperkeratosis or aberrant scars (data not shown). The histopathological study demonstrated the thickening of all cutaneous layers in comparison with healthy skin with a remarkable ortho-keratotic hyperkeratosis, acanthosis and dermal fibrosis (Figure 1E).

\section{Therapeutical Assay in S. aureus Infection Model}

A summary of the clinical, microbiological and histological changes induced by the different treatments are listed in order of the magnitude of the effect in Table 1. Significant effects were demonstrated with all therapeutic approaches in our model of cutaneous $S$. aureus infection, in terms of clinical healing, cosmetic result (Table 2), histopathological events, and microbial burdens.

\section{Clinical Results}

Wounds on therapy healed significantly before than wounds untreated: 7.18 (SD 1.00) days for MB-aPDT; 9.33 (SD 1.86) days for $\mathrm{MU}$ and also for the combination, and finally 10.33 (SD 1.0) days for controls $(p<0.001)$. When the different therapies were compared, MB-aPDT was statistically significant better than the combination $(p=0.001)$ or MU alone $(p=0.041)$.

The smallest size of the wound was achieved with MB-aPDT $(0.21 \pm 0.11 \mathrm{~mm})$, followed by $\mathrm{MU}(0.33 \pm 0.15 \mathrm{~mm})$ and finally the combination $(0.37 \pm 0.17 \mathrm{~mm})$ and all of them significantly smaller than without treatment. The size of the wound is one of most significant parameters correlated with others (Table 3) and also the microbial burden showing differences among therapies (Table 4). In the post-hoc comparisons, MBaPDT was significantly better in terms of decreasing the size of the wound than MU and the combination (Table 4). Regarding the mean number of days for crust loss, this was significantly lower with MB-aPDT $(4.69 \pm 0.70)$ than with any other treatment $(p<0.001)$. It is surprising that the number of days for crust loss was significantly higher with MU (5.94 \pm 1.24$)$ than without any treatment $(5.17 \pm 1.07)$ $(p=0.44)$.

Regarding the qualitative aspects of the wounds infected with $S$. aureus on therapy (Table 2), MB-aPDT induces less purulent scabbing either in number of samples (24 vs. $76 \%)$ and in the size ( $0 \%$ exuberant vs. $20 \%)$ than the rest of the treatments $(p=$ 0.44 ); additionally, the erythema was less frequent, being present in $13 \%$ of the lesions treated with MB-aPDT vs. in $87 \%$ of the wound receiving other treatments $(p<0.44)$. In fact, the most remarkable difference was in erythema, present until the third day in all wounds, but being more intense in those treated with MU alone than in the wounds with MB-aPDT or the combination (Figure 3). Regarding the presence of scaling, it was only seen in $36 \%$ of the lesions treated with MB-aPDT vs. in $60 \%$ of the aPDT-untreated $(p=0.44)$. 


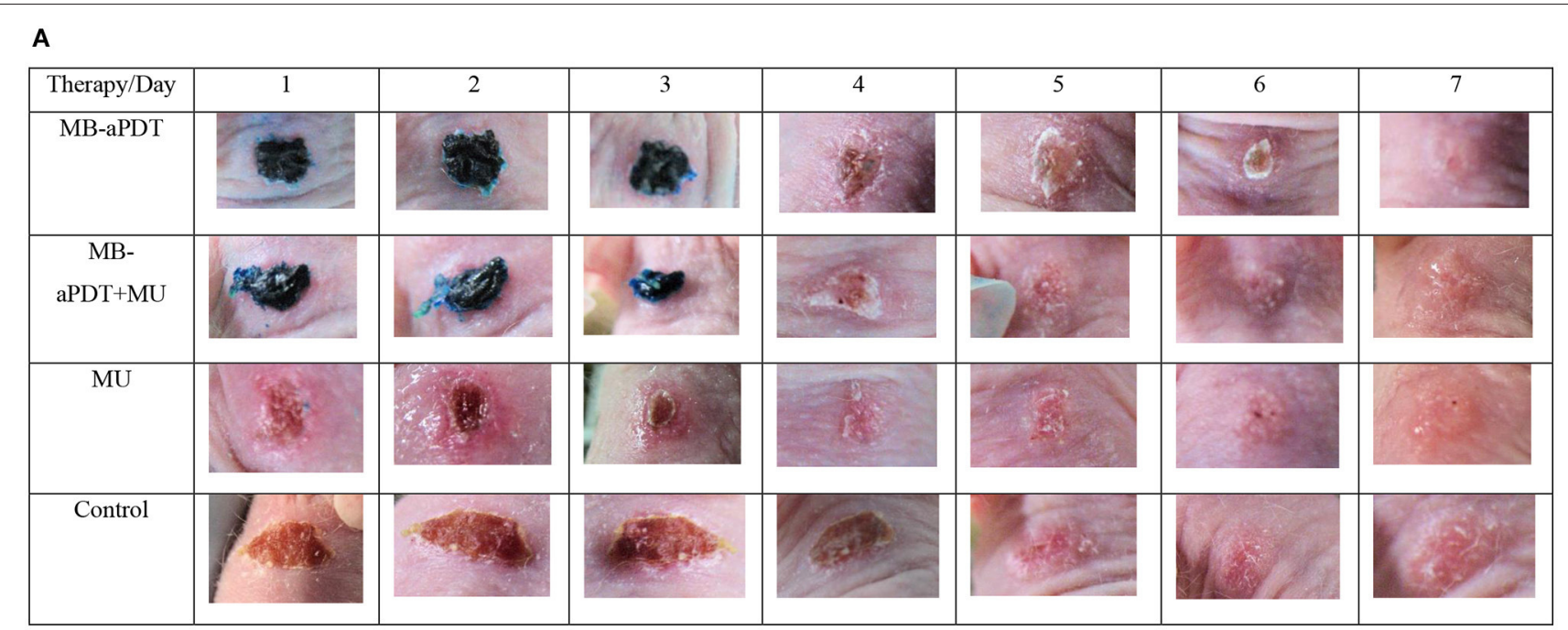

B

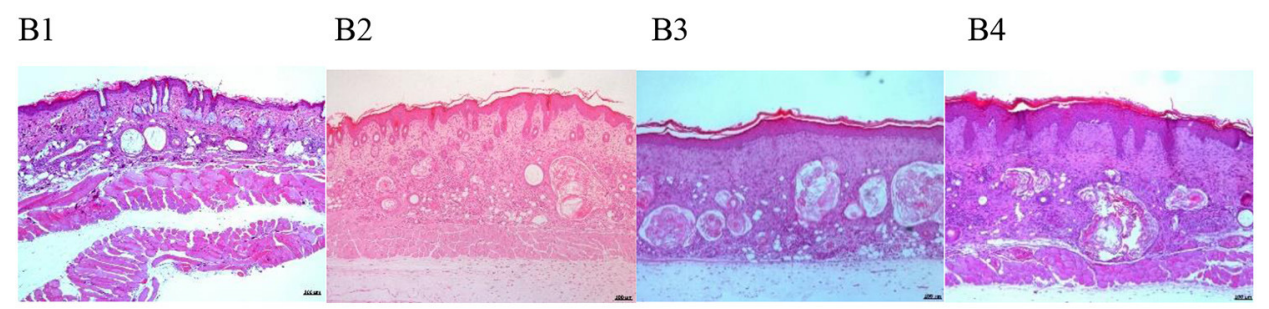

FIGURE 3 | Comparison of photographs (A)/microphotographs (B). (A) Clinical evolution of wounds infected by S. aureus during 7 days on therapeutical challenge and (B) healthy skin and infected wounds in function of therapy. (A) Photographs. (B) Microphotographs. From the left to the right of the image. (B1) Normal skin showing the mild undulation of the epidermis, thin dermis, dilated empty follicles typically observed in nude mice, and the muscle layer. $\mathrm{H}$-E. $\mathrm{x} 50$. (B2) aPDT-treated wound. Note the mild acanthosis and mild undulation of the epidermis, a thicker dermis with moderate dermal fibrosis and more dilated follicles with abundant keratin and granulomatous inflammation. H-E. x50. (B3) aPDT+MU-treated wound. Epidermis shows slightly more acanthosis and orthokeratotic hyperkeratosis, slightly more cellularity in the dermis and more follicular reaction than aPDTtreated wounds. H-E. x50. (B4). MU-treated wound. Note intense acanthosis with abundant rete pegs and orthokeratotic hyperkeratosis, a slightly thinner dermis and a marked follicular reaction. H-E. x50.

The most outstanding qualitative effect in the lesions treated exclusively with MU was the presence of scaling in $70 \%$ of the lesions, intense in $50 \%$ of them $(p=0.44)$ (Table 2). The combination of both treatments (MB-aPDT + MU) significantly reduced the erythema, present in 1 out of 4 lesions (25\%) vs. in $75 \%$ of the lesions treated with MU and $45 \%$ of the untreated wounds $(p=0.44)$. The combination also reduced purulent scabs, absent in $77 \%$ of those treated with it and also from the qualitative point of view ( $0 \%$ of exuberant cases vs $15 \%$ in the untreated group) $(p=0.44)$. Finally, the combination also was superior to $\mathrm{MU}$ alone in terms of healing proportion ( $32 \%$ vs. $15 \%, p=0.44$ ). MU is the therapy that perpetuate crusts more even than untreated wounds in contrast to MB-aPDT (Table 4).

MB-aPDT is the treatment that cause scarfree benefits (Table 2) when scar was absent in $85 \%$ of the wounds treated with it comparing to presence of scar in 53\% (43\% hypertrophic) in those receiving MU or the combination (Figure 3).

\section{Microbiological Results}

$\mathrm{MU}\left(0.677-\log _{10} \pm 1.346\right)$ and the combination of MB-aPDT + MU (0.950- $\left.\log _{10} \pm 1.552\right)$ achieved the lowest microbiological count without statistically significant differences between them (Table 4). MU was superior than MB-aPDT (1.464- $\log _{10} \pm 1.740$; $p=0.025)$ in terms of microbiological reduction.

\section{Histological Results}

Figure 1 shows the histological differences between the normal skin of the mice and the skin of the wound after spontaneous healing or the treatments. A remarkable increase in the thickness either of the epidermis or the dermis is observed (Figure 1E). Comparing the histological events induced by the different treatments, the thickness of the skin layers was lower with MU, followed by MB-aPDT and finally by the combination than of controls ( $p=0.007$ for dermal thickness) (Table 5). Dermal fibrosis and thickening were more present in wounds treated with MB-aPDT compared with a more intense epidermal reaction 
(acanthosis, rete ridges), hyperkeratosis and follicular cysts in those treated with MU alone (Figure 3B). In fact, the percentage of samples with intense increase in connective tissue and cellularity in the dermis was achieved with MB-aPDT (50\%), even though the differences were not statistically different (Table 5). The increase in the size and also the number of follicular cyst size was more frequent in those samples treated with MU than with the other treatments, being the differences in the follicular cyst size statistically significant $(p=0.033)$. Variability of histological data on skin of SKH-1 mice are illustrated in Figure 4.

\section{DISCUSSION}

The current study shows that the three treatment protocols tested, MB-aPDT, MU, and MB-aPDT +MU, were beneficial compared to self-healing; whereas mupirocin showed the higher logaritmic reduction of $S$. aureus, MB-aPDT was better in the speed wound healing and cosmetic result. The experimental

TABLE 1 | Ranking of the different treatments for the statistically clinical, cosmetic, histological, and microbiological variables.

\section{Significant benefits of therapy \\ Clinical healing \\ Size \\ Size reduction \\ $50 \%$ Size reduction \\ Crust Loss \\ Purulence \\ Contraction \\ Erythema \\ Clinical cure (days) \\ Cosmetic results \\ Scarless \\ Histopathology findings \\ Thickness hyperkeratosis \\ Dermis thickness \\ Size follicular cyst \\ Microbial count \\ $\log _{10}$

$$
\begin{aligned}
& \text { aPDT }>\text { MU }>\text { aPDT-MU }>\text { Control } \\
& \text { aPDT }>\text { aPDT-MU }>M U>\text { Control } \\
& \text { aPDT }<\text { aPDT-MU }<M U<\text { Control } \\
& \text { aPDT }<\text { PDT-MU } \\
& \text { aPDT (24 h) } \\
& \text { aPDT }<\text { aPDT-MU } \\
& \text { aPDT }<\text { aPDT-MU }<M U<\text { Control } \\
& \text { aPDT }<\text { aPDT-MU }=M U<\text { Control } \\
& \mathrm{MU}<\text { aPDT }<\text { aPDT-MU } \\
& \mathrm{MU}<\text { aPDT }<\text { aPDT-MU } \\
& \mathrm{MU}<\text { aPDT-MU }<\text { aPDT } \\
& \mathrm{MU}<\mathrm{aPDT}-\mathrm{MU}<\mathrm{aPDT}<\text { Control }
\end{aligned}
$$

aPDT, antimicrobial photodynamic therapy; MU, mupirocin. model of abrasive superficial S. aureus-infection wound in SKH1 hairless mice is not useful enough for pre-clinical studies to establish the efficacy of antimicrobial treatments, although its self-healing condition could have limited the evaluation of synergistic effects in our study.

Our abrasive skin wound is more similar to real infection than tape stripping (45) and needs a higher bacterial inoculum $(21,34)$. Clinically, is very similar to human impetigo, with a purulent infection established in $24 \mathrm{~h}$, dermis affection and pyogranuloma during maturation of $S$. aureus at $48 \mathrm{~h}$, epidermal purulent micro-abscess $(72 \mathrm{~h})$ and contraction and large crust of purulent material with histopathological hyperkeratosis $(96 \mathrm{~h})$ $(18,46,47)$. Wounds healed per se appear with significative thickening of skin layers and dermal epithelial cysts, typical of this hairless mouse model, and clinically with desquamation and hypertrophic scar $(16,23,48)$.

MB-aPDT was better than the treatment with MU in terms of healing speed of the wound and cosmetic result. This reduction of size of wound cited by Topaloglu et al. (49) and crust loss in days, shows evident differences in favor of aPDT as described by Dai et al. (34). Not only changes in size wound but also significative contraction in the first day after MB-aPDT in comparison with $72 \mathrm{~h}$ of untreated wounds. By contrast, MU treatment achieves the highest microbiological reduction. This apparent discordance between microbiological and clinical healing has been previously reported in Wistar rats, where topical MU shows efficacy against wound infection inoculated with S. aureus (50). Furthermore, the count of bacteria from infected mice may be inconsistent (51) and for that reason, other methods can be recommended in addition as bioluminescent monitoring (52) or the culture of supernatant of skin (47).

Regarding the combination of both treatments, MB-aPDT + MU was neither superior than MB-aPDT, in terms of clinical healing of the infected wound, nor than MU, in terms of microbiological cure, and its results seem to be nearest from MU

\begin{tabular}{|c|c|c|c|c|c|}
\hline $\begin{array}{l}\text { Parameter } \\
\text { Treatment }\end{array}$ & Purulence & Erythema & Healed aspect & Scaling & Scarless \\
\hline aPDT & $0.0002(0.398)$ & $<0.0001$ & $0.0005(0.402)$ & 0.0329 & $<0.0001(0.425)$ \\
\hline $\mathrm{MU}$ & - & - & - & $<0.0088$ & - \\
\hline
\end{tabular}
than from MB-aPDT. Therefore, the combination did not seem to have a synergistic effect in contrast to what is shown in the in vitro study performed by our group (53). One explanation could be that in the in vitro and in vivo concentration of MU used were not the same and neither the bactericidal effect. In vivo experiment was carried out using the concentration of MU used to treat cutaneous infections (54), while in the in vitro study, the concentration of MU used did not significantly reduce the bacterial load by itself (53). Other possible explanation is the disadvantage of our animal model in which the infected wounds

TABLE 2 | Significant $p$-value and (V-Cramer) for qualitative aspects of wounds on therapy compared with untreated infected wounds.

Chi Square/Fisher Exact $p$-value. (Table shows only significative V Cramer: $v>0.3$ ).

aPDT, antimicrobial photodynamic therapy; MU, mupirocin. 
TABLE 3 | Significant correlations (Pearson coefficient) and p-values and in numerical parameters for wounds in model assay (control) and wounds on therapy.

\begin{tabular}{|c|c|c|c|c|}
\hline $\begin{array}{l}\text { Correlations } \\
\text { Pearson Coeficient } \\
\text { (p-value) }\end{array}$ & Control & aPDT & aPDT + MU & MU \\
\hline Size vs. $\log _{10}$ bacteria & $0.7^{\mathrm{a}}(<0.0001)$ & $0.48(<0,0001)$ & $0.58(<0.0001)$ & $0.6^{\mathrm{a}}(<0.0001)$ \\
\hline Size vs. Crust loss & $0.44(<0.0001)$ & $0.46^{b}(<0.0001)$ & $0.19(0.0360)$ & $0.3(<0.0001)$ \\
\hline Crust loss-SR50\% & $0.33(0.0048)$ & $0.39^{\mathrm{b}}(<0.0001)$ & $0.28(0.0015)$ & - \\
\hline
\end{tabular}

Measures: Size wounds (cm); $\log _{10}$ (CFU/ml); Crust loss (CL. days): SR 50\%: size reduction to $50 \%$ original (days).

${ }^{*}$ Pearson coeficient: High: > 0.7; Moderate: 0.3-0.7; Mild < 0.3.

${ }^{a}$ Antimicrobial and size of wound. ${ }^{b}$ Wound healing.

aPDT, photodynamic therapy; MU, mupirocin.

TABLE 4 | Multiple comparison of quantitative effects of the different treatment vs. untreated wounds.

\begin{tabular}{|c|c|c|c|c|c|}
\hline Parameter ( $p$-value) & Treatment & $N$ & Mean \pm SD & $\begin{array}{l}\text { Significant } \\
\text { Comparisons }\end{array}$ & $P^{\star}$-value \\
\hline $\begin{array}{l}\text { Final microbiological } \\
\text { count }\left(\log _{10}\right) \\
\text { (NS) }\end{array}$ & $\begin{array}{l}\text { aPDT } \\
\text { aPDT + MU } \\
\text { MU } \\
\text { Control }\end{array}$ & $\begin{array}{l}52 \\
56 \\
36 \\
55\end{array}$ & $\begin{array}{l}1.464 \pm 1.740 \\
0.950 \pm 1.552 \\
0.677 \pm 1.346 \\
1.711 \pm 2.124\end{array}$ & $\begin{array}{l}\text { MU vs. aPDT } \\
\text { aPDT+MU vs. control } \\
\text { MU vs. control }\end{array}$ & $\begin{array}{l}0.0250 \\
0.0332 \\
0.0110\end{array}$ \\
\hline $\begin{array}{l}\text { Size }(\mathrm{cm}) \\
(<0.0001)\end{array}$ & $\begin{array}{l}\text { aPDT } \\
\text { aPDT + MU } \\
\text { MU } \\
\text { Control }\end{array}$ & $\begin{array}{l}52 \\
56 \\
36 \\
55\end{array}$ & $\begin{array}{l}0.208 \pm 0.113 \\
0.371 \pm 0.169 \\
0.328 \pm 0.145 \\
0.430 \pm 0.105\end{array}$ & $\begin{array}{l}\text { aPDT vs. aPDT+MU } \\
\text { aPDT vs. MU } \\
\text { aPDT + MU vs. control } \\
\text { aPDT vs. control } \\
\text { MU vs. control }\end{array}$ & $\begin{array}{c}<0.0001 \\
<0.0001 \\
0.0287 \\
<0.0001 \\
0.0002\end{array}$ \\
\hline $\begin{array}{l}\text { Crust loss } \\
\text { (days) } \\
(<0.0001)\end{array}$ & $\begin{array}{l}\text { aPDT } \\
\text { aPDT + MU } \\
\text { MU } \\
\text { Control }\end{array}$ & $\begin{array}{l}52 \\
56 \\
36 \\
78\end{array}$ & $\begin{array}{l}4.692 \pm 0.701 \\
5.643 \pm 1.069 \\
5.944 \pm 1.241 \\
5.167 \pm 1.074\end{array}$ & $\begin{array}{l}\text { aPDT vs. aPDT + MU } \\
\text { aPDT vs. MU } \\
\text { aPDT+MU vs. control } \\
\text { aPDT vs. control } \\
\text { MU vs. control }\end{array}$ & $\begin{array}{c}<0.0001 \\
<0.0001 \\
0.0124 \\
0.0058 \\
0.0009\end{array}$ \\
\hline $\begin{array}{l}\text { Size reduction } \\
50 \% \text { (days) } \\
(<0.0001)\end{array}$ & $\begin{array}{l}\text { aPDT } \\
\text { aPDT + MU } \\
\text { MU } \\
\text { Control }\end{array}$ & $\begin{array}{l}52 \\
56 \\
36 \\
78\end{array}$ & $\begin{array}{l}5.327 \pm 0.706 \\
7.125 \pm 1.466 \\
8.472 \pm 2.569 \\
10.667 \pm 1.898\end{array}$ & $\begin{array}{l}\text { aPDT vs. aPDT+MU } \\
\text { MU vs. aPDT + MU } \\
\text { aPDT vs. MU } \\
\text { aPDT + MU vs. control } \\
\text { aPDT vs. control } \\
\text { MU vs. control }\end{array}$ & $\begin{aligned}< & 0.0001 \\
& 0.0019 \\
< & 0.0001 \\
< & 0.0001 \\
< & 0.0001 \\
< & 0.0001\end{aligned}$ \\
\hline
\end{tabular}

*Kruskal Wallis (p significative). aPDT, antimicrobial photodynamic therapy; MU, mupirocin.

spontaneously healed in 10-12 days. To our knowledge, there are not murine studies using aPDT combined with MU in infected abrasive wounds. However, there are accelerated healing infected assays recently described $(55,56)$. Besides, most of the studied combinations using aPDT + antimicrobial tried so far were not designed about approved standards, making difficult to compare the results $(38,40,57)$.

The good results in the scarring process shown by MB-aPDT (alone or combined vs. MU) correlates with the presence of more connective tissue in histology and also cellularity in the dermis (fibroblasts). It has been shown that aPDT induces fibroblasts proliferation and, consequently, an increase of collagen and elastin with better healing activity (58). Contraction in the chronology of the wound healing is an early event with MB-aPDT ( $24 \mathrm{~h}$ post-aPDT) that reduces the size because of the centripetal movement of the wound margins (50) even combined with MU. Reports are inconclusive, with Bairy et al. (59) who detected contraction in burns treated with MU in rats, whereas Erdur et al., did not observe any contraction (50). Experimental factors such as type of animal or cutaneous response could explain these contradictions.

Histopathology is the gold standard method to measure wound healing and to determine re-epithelialization of epidermis (43, 60-62). Skin of hairless mice, free of rete pegs, develops a pseudo-epitheliomatous hyperplasia during healing, similar to the human rete pegs, source of keratinocytes during skin healing (63). Rete pegs, in our study, were only present in MB-aPDT wounds besides a more conjunctive tissue response (Table 5) by hyperplasticity of epidermis in nude mice described in 1952 (48). Treatment reduces dermal response and histopathological hyperkeratosis, asynchrony dermis/epidermis (16) and increase of size of cysts, not referred before (Table 5). Infected abrasions treated showed lesser inflammatory findings during the MU treatment and more conjunctive response of aPDT as reported Jorge et al. (64) in nude mice without cyst changes, in contrast with 
TABLE 5 | Histologic findings of wounds on therapy against untreated and healthy skin.

\begin{tabular}{|c|c|c|c|c|c|c|}
\hline $\begin{array}{l}\text { Level of Increase and wound } \\
\text { examined }\end{array}$ & aPDT $N(\%)$ & $\begin{array}{c}\text { aPDT+MU N } \\
(\%)\end{array}$ & MU N (\%) & $\begin{array}{l}\text { No } \\
\text { treatment }\end{array}$ & Healthy skin & $P$-value \\
\hline Conjunctive tissue & & & & & & 0.951 \\
\hline -Mild & 2 (33.3) & $2(40)$ & $0(0)$ & $1(50)$ & & \\
\hline -Moderate & $1(16.7)$ & $2(40)$ & 5 (83.3) & $0(0)$ & & \\
\hline -Intense & $3(50.0)$ & $1(20)$ & $1(16.7)$ & $1(50)$ & & \\
\hline Cellularity & & & & & & 0.695 \\
\hline -Mild & $1(16.7)$ & $2(40)$ & $0(0)$ & $1(50)$ & & \\
\hline -Moderate & 2 (33.3) & $2(40)$ & 5 (83.3) & $1(50)$ & & \\
\hline -Intense & $3(50)$ & $1(20)$ & $1(16.7)$ & $0(0)$ & & \\
\hline Rete ridge & & & & & & 0.430 \\
\hline -Mild & $2(40)$ & $3(75)$ & $0(0)$ & $1(50)$ & & \\
\hline -Moderate & $2(40)$ & $1(25)$ & $4(66.7)$ & $0(0)$ & & \\
\hline -Intense & $1(20)$ & $0(0)$ & 2 (33.3) & $1(50)$ & & \\
\hline Follicular Cyst size & & & & & & $0.033^{\star}$ \\
\hline -Mild & 2 (33.3) & 2 (33.3) & $0(0)$ & $1(50)$ & & \\
\hline -Moderate & $3(50)$ & $1(16.7)$ & 2 (33.3) & $1(50)$ & & \\
\hline -Intense & $1(16.7)$ & $3(50)$ & $4(66.7)$ & $0(0)$ & & \\
\hline Follicular Cyst number & & & & & & 0.111 \\
\hline -Mild & $3(50)$ & 2 (33.3) & $1(16.7)$ & $1(50)$ & & \\
\hline -Moderate & 2 (33.3) & $1(16.7)$ & 2 (33.3) & $1(50)$ & & \\
\hline -Intense & 1 (16.7) & $3(50)$ & $3(50.0)$ & $0(0)$ & & \\
\hline $\begin{array}{l}\text { Epidermis Thickness ( } \mu \mathrm{m}) \\
\text { (mean, SD) }\end{array}$ & $\begin{array}{c}230.51 \\
(166.38)\end{array}$ & $\begin{array}{l}209.13 \\
(120.20)\end{array}$ & $\begin{array}{l}122.99 \\
(78.89)\end{array}$ & $\begin{array}{c}370.82 \\
(266.92)\end{array}$ & $18.93(1.04)$ & 0.118 \\
\hline $\begin{array}{l}\text { Dermis thickness } \\
(\mu \mathrm{m})(\text { mean, SD) }\end{array}$ & $\begin{array}{c}866.71 \\
(217.90)\end{array}$ & $\begin{array}{l}918.09 \\
(217.88)\end{array}$ & $\begin{array}{l}706.09 \\
(69.01)\end{array}$ & $\begin{array}{l}1092.14 \\
(216.53)\end{array}$ & $\begin{array}{c}346.39 \\
(104.73)\end{array}$ & $0.007^{\star}$ \\
\hline $\begin{array}{l}\text { Hyperkeratosis thickness }(\mu \mathrm{m}) \\
\text { (mean, SD) }\end{array}$ & 44.34 (36.75) & 63.71 (39.98) & 33.37 (8.52) & 152.16 & 8.76 (3.98) & $0.013^{\star}$ \\
\hline
\end{tabular}

${ }^{\star} p<0.05$ significative; aPDT, antimicrobial photodynamic therapy; MU, mupirocin.

our findings (Figure 3B4). Epidermis on therapy showed more hyperkeratosis than acanthosis (65) representing a recovery way of healing of this superficial model of $S$. aureus in nude mice (66).

Erythema, non-detachment of crust and bigger cyts are irritative effects during MU therapy, to our knowledge first described. Erythema, is the main component of purulent erythematous dermatitis in humans (28) and was present with all therapies, being more remarkable in MU treated wounds, although always milder than in untreated wounds. A previous report in a mouse model of wound infected with methicillinresistant $S$. aureus shows the same degree of inflammatory infiltrate at $24 \mathrm{~h}$ of MB-aPDT as without treatment (67); we do not know how to explain this difference considering that $2 \% \mathrm{MU}$ (Bactroban) has little or no potential for irritation in previous studies (54). In our opinion, erythema during treatment with MU is a clinical sign related with an irritative response more than a weakened inflammatory control as the histological study demonstrates (Table 5).

In the present study MU shows the worse clinical parameters of the three treatments in terms of the clinical evolution of the infected wound. In fact, delayed detachment of the crust was significantly abnormal for MU wounds, even more retarded than untreated wounds (Table 4). Speculations about unknown role of crusts in the microbial clearance of $S$. aureus (67) does not explain this delay in MU wounds because the microbial reduction was the highest. An increase of tissue force with higher resistance of the scar due to organization of collagen may justify this detected delay (68). Without evident detrimental effects on healing (69), MU could injure keratinocytes and fibroblasts of healthy skin (68) what stimulates new formulations (70) or synergistic antimicrobial combinations with best healing properties (71). Hyperkeratosis/clinical desquamation in MU-wounds shows clinical-histological correspondence with an excess of keratin production and superficial cutaneous desquamation in nude mice (23); this could have a double explanation: uncontrolled wound healing in untreated wounds or changes of lipid layer of skin as secondary effect of repetitive dose of topical MU in humans (drug commercial package) and possibly in SKH-1 mice. The last significative finding due to repetitive administration of $\mathrm{MU}$ ointment on SKH-1 mice is larger follicular cyst, to our knowledge, described for the first time (Table 5).

Our clinical results agree with the already reported beneficial effect of aPDT on healing of $S$. aureus infected wounds in other models $(34,49,72,73,77)$ and also in human patients (75). Furthermore, our clinical results add evidence about that MB-aPDT in particular improves the healing of different causal agent-infected skin wounds as previously was demonstrated by our group in sheep (74), 


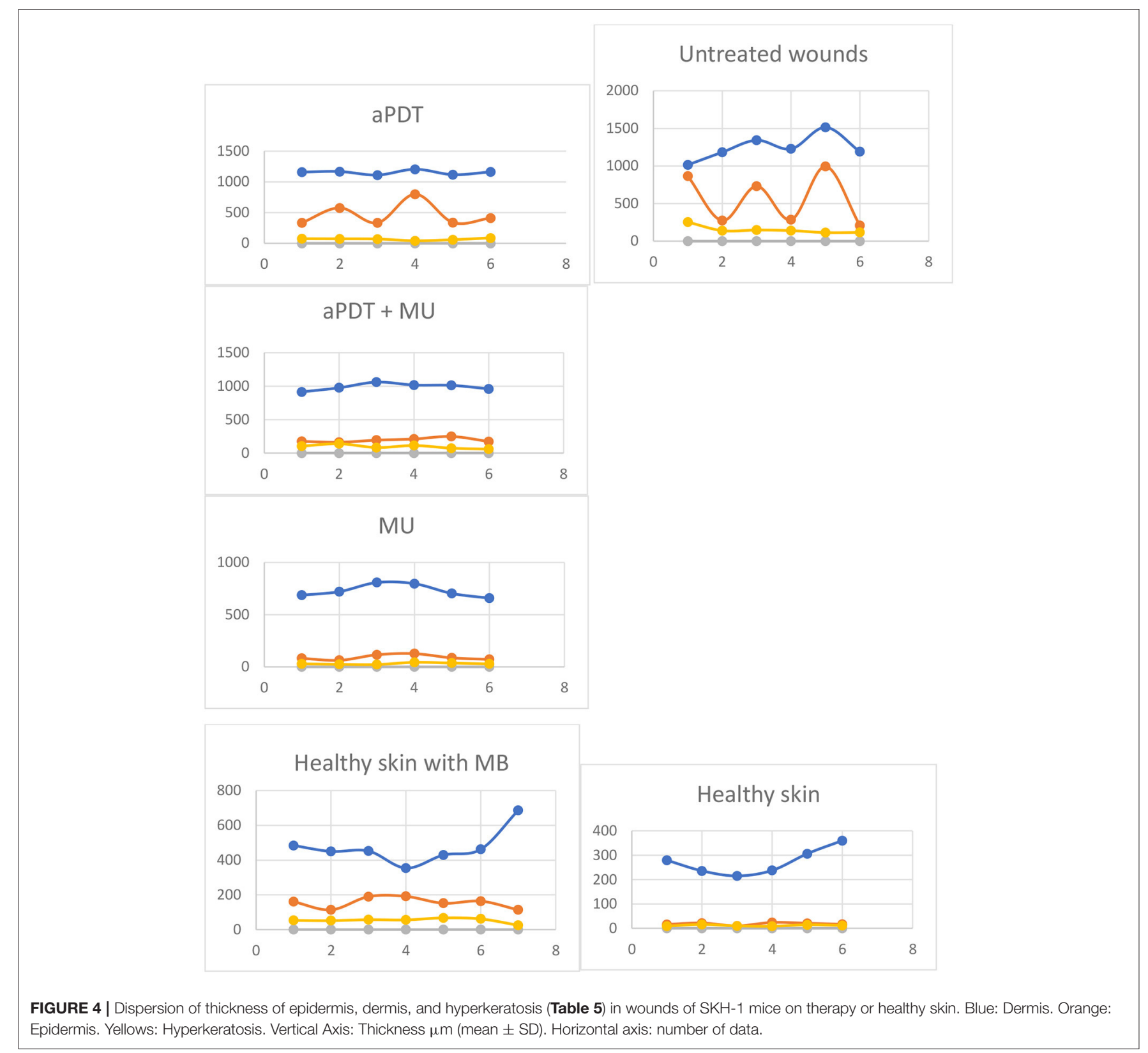

recently in cattle (76) and it has been equally reported in humans (27).

Here, we present a complete correspondence of biological, clinical, and histopathological findings in a superficial abrasive model of S. aureus infection in SKH-1 mice. Chronology in clinical signs (78) of cutaneous events during therapy promotes contraction and detachment of crust as highlighted indexes of wound healing. Correlations as size lesion and bacterial count in this SKH-1 model (78), size lesion changes and healing during aPDT treatment (79) were corroborated. Self-limiting of this model (23), related with experimental factors (skin reparation), promotes the clearing of bacteria $(10,40)$; being a disadvantage to achieve a most robust model of skin $S$. aureus infection, on the other hand the lack of epidermis is an excellent model of repeated abrasion caused by human scratching (47). A more robust model of infection may find more synergistic results that those presented here. Antimicrobial failure and synergy response were cited $(80,81)$. Nevertheless, this model has two main limitations: first, the fact that even without treatment the infection and the wound cured in an immunocompetent model (47) although correlation of clinical events and histopathological findings are strong in staphylococcal infections (78), second, the lack of males, because both skin layer differences by gender have been described $(18,82)$. Additionally, biological variability of SKH-1 hairless mice (23) during wound healing (66) should be considered. These results in animals support 
to carry out clinical trials to use MB-PDT in infected wounds evaluating not only the microbiological clinical effect against $S$. aureus infections but also to stimulate wound healing (75).

\section{CONCLUSIONS}

Clinical signs, gross observations, and histopathological findings are concurrent in this abrasive infection model. Superficial wounds on therapy with one session of MB-aPDT have shorter clinical duration, contraction with best healing and good recuperation, whereas $\mathrm{MU}$-wounds achieve the best antimicrobial/anti-inflammation control. The increase of size of follicular cyst on the wounded skin of SKH-1 mice and skin asynchrony that produces therapies are significative, considering variability of data in nude mice. We did not found benefits in combining MB-aPDT + MU in our experimental model of wound superficial infection with $S$. aureus in SKH-1 hairless mice; further studies, in a model without the capacity of selfresolution of the infected wound and also using MU resistant $S$. aureus strains, are needed in order to confirm these results and discard the possible usefulness of this combination. However, this study provides clear evidence on the usefulness of the MB-aPDT, so it can help to support its use in the clinic and we hope that it will help to extend its antimicrobial and healing application. Its main advantage arises from being an alternative treatment without using antibiotics, therefore it will not contribute to the selection of resistant strains, and the efficacy is independent of the pattern of antimicrobial resistance of the strains implicated in the infection. Skin benefits has been demonstrated for healing use of MB-aPDT in clinical practice.

\section{REFERENCES}

1. Jeong S, Kim HY, Kim AR, Yun CH, Han SH. Propionate ameliorates $S$. aureus skin infection by attenuating bacterial growth. Front Microbiol. (2019) 10:1363. doi: 10.3389/fmicb.2019. 01363

2. Kopecki Z, Ogunniyi D, Trott DJ, Cowin AJ. Fighting chronic wound infection- one model at a time. Wound Pract Res. (2017) 25:6-13. Available online at: http://hdl.handle.net/2440/118543

3. Trøstrup H, Thomsen K, Calum HP, Høiby N, Moser CE. Animal models of chronic wound care. Chronic Wound Care Manage. Res. (2016) 3:12332. doi: 10.2147/CWCMR.S84361

4. Sayedyahossein S, Xu SX, Rudkouskaya A, McGavin MJ, Dagnino L, et al. Staphylococcus aureus keratinocyte invasion is mediated by integrinlinked kinase and Racl. FASEB J. (2015) 29:711-23. doi: 10.1096/fj.14-2 62774

5. Mölne L, Tarkowski A. An experimental model of cutaneous infection induced by superantigen producing Staphylococcus aureus. J Invest Dermatol. (2000) 114:1120-5. doi: 10.1046/j.1523-1747.2000.00973.x

6. Kim HK, Missiakas D, Schneewind O. Mouse models for infectious diseases caused by Staphylococcus aureus. J Immunol Methods. (2014) 410:8899. doi: 10.1016/j.jim.2014.04.007

7. Dharmaratne P, Sapugahawattem DN, Wang B, Chan CL, Lau KM, Fung KP, et al. Contemporary approaches and future perspectives of bacterial therapy (aPDT) against methicillin-resistant Staphylococcus aureus (MRSA): a systematic review. Europ J Med Chem. (2020) 200:112341. doi: 10.1016/j.ejmech.2020.112341

\section{DATA AVAILABILITY STATEMENT}

The raw data supporting the conclusions of this article will be made available by the authors, without undue reservation.

\section{ETHICS STATEMENT}

The animal study was reviewed and approved by Ethic Committee for Animal Experiments from the University of Zaragoza (PI40/13).

\section{AUTHOR CONTRIBUTIONS}

MP and MV participated equally in the design, conducted all animal experiments, and performed and draft this manuscript. PR develop microbiological procedures and participated in the design. YG, AR, and CA participated equally at the design of experiment, statistically results, and design of these experiments. $\mathrm{RB}$ and $\mathrm{BM}$ elaborated histopathological procedures and its interpretation. VP-L contributes with his knowledge on S. aureus and MB-aPDT. All authors read and approved this manuscript.

\section{FUNDING}

This work was partially supported by the grant Seinorte 2016 in Spain. Statistically procedures in animals were performed by A. Fernandez-Casasnovas (DVM, Ph.D.) at the Animal Pathology of Veterinary Faculty, University of Zaragoza (Spain). Authors were very grateful with CIBA (Centro de Investigaciones Biomédicas de Aragón, Zaragoza, Spain) and with Sevilla's researchers (García-Luque, I., Ballesta, S). Angela Lloveras checked the grammar.

8. Guo Y, Song G, Sun M, Wang J, Wang Y. Prevalence and therapies of antibiotic-resistance in Staphylococcus aureus. Front Cell Infect Microbiol. (2020) 10:107. doi: 10.3389/fcimb.2020.00107

9. Trübe P, Hertlein T, Mronchen DM, Jorde I, Krause B, Zeun J, et al. Bringing together what belongs together: optimizing murine infection models by using mouse-adapted Staphylococcus aureus strains. Internat J Med Microbiol. (2018) 309:26-38. doi: 10.1016/j.ijmm.2018.10.007

10. Schulz D, Grumann D, Trübe P, Pritchett-Corning K, Johnson S, Reppschälger $\mathrm{K}$, et al. Laboratory mice are frequently colonized with staphylococcus aureus and mount a systemic immune response- note of caution for in vivo infection experiments. Front Cell Infect Microbiol. (2017) 7:152. doi: 10.3389/fcimb.2017.00152

11. Holtfreter S, Radcliff FJ, Grumann D, Read H, Johnson S, Monecke S, et al. Characterization of a mouse-adapted Staphylococcus aureus strain. PLoS ONE. (2013) 8:e71142. doi: 10.1371/journal.pone.0071142

12. Palero JA, de Brujin $H$, van der Ploeg van den Heuvel A, Sterenborg HJCM, Gerritsen HC. Spectrally resolved multiphoton imaging of in vivo and excised mouse skin tissues. Biophysical Journal, Volume. (2007) 93:9921007. doi: 10.1529/biophysj.106.099457

13. Krutmann J, Humbert P. Nutrition for Healthy Skin. Berlin; Heidelberg: Springer (2011). doi: 10.1007/978-3-642-12264-4

14. Onunkwo CH, Hahn BL, Sohnie PG. Clearance of experimental cutaneous Staphylococcus aureus infections in mice. Arch Dermatol Res. (2010) 302:37582. doi: 10.1007/s00403-010-1030-y

15. Silva ZS, Bussadori SK, Fernandez KP, Huang YY, Hamblin MR. Animal models for photodynamic therapy (PDT). Biosc Rep. (2015) 35:e00265. doi: 10.1042/BSR20150188 
16. Cela EM. Exposición cutánea a la radiación Ultravioleta. Implicancias sobre funciones del sistema inmune. master's thesis. Universidad de Buenos Aires, Facultad de Farmacia y Bioquímica, Argentina (2016). 171. p.

17. Dellambra E, Odorisio T, D’Arcangelo D, Failla CM, Facchiano A. Non-animal models in dermatological research. Altex. (2019) 36:177202. doi: 10.14573/altex.1808022

18. Hoffmann JP, Friedman JK, Wang Y, McLachlan JB, Sammarco MC, Morici LA, et al. In situ treatment with novel microbicide inhibits Methycillin Resistant Staphylococcus aureus in a murine wound infection model. Front Microbiol. (2020) 10:3106. doi: 10.3389/fmicb.2019.03106

19. Aragona M, Dekoninck S, Rulands S, Lengled S, Mascré G, Simons BD, et al. Defining stem cell dynamics and migration during wound healing in mouse skin epidermis. Nat Commun. (2017) 8:14684. doi: 10.1038/ncomms14684

20. Dai T, Gupta A, Huang YY, Sherwood ME, Murray CK, Vrahas MS, et al. blue light eliminates community-acquired methicillin-resistant Staphylococcus aureus in infected mouse skin abrasions. Photomed Laser Surg. (2013) 31:5318. doi: $10.1089 /$ pho. 2012.3365

21. Kugelberg E, Norström T, Petersen TK, Duvold T, Andersson DI, Hughes D. Establishment of a superficial skin infection model in mice by using Staphylococcus aureus and Streptococcus pyogenes. Antimicrob Agents Chemother. (2005) 49:3435-441. doi: 10.1128/AAC.49.8.3435-3441.2005

22. Roche ED, Renick PJ, Tetens SP, Carson DL. A Model for evaluating topical antimicrobial efficacy against methicillin-resistant Staphylococcus aureus biofilms in superficial murine wounds. Antimicrob Agents Chemother. (2012) 56:4508-10. doi: 10.1128/AAC.00467-12

23. Benavides F, Oberyszynb TM, VanBuskirkc AM, Reeved VE, Kusewitta DF. The hairless mouse in skin research. J Dermatol Sci. (2009) 53:1018. doi: 10.1016/j.jdermsci.2008.08.012

24. Banerjee S, Argaez C. Topical Antibiotics for Infection Prevention: A Review of the Clinical Effectiveness and Guidelines. Ottawa, ON: Canadian Agency for Drugs and Technologies in Health (2017).

25. Khoshnood S, Heidary M, Asadi A, Soleimani S, Motahar M, Savari M, et al. A review on mechanism of action, resistance, synergism, and clinical implications of mupirocin against Staphylococcus aureus. Biopha. (2019) 109:1809-18. doi: 10.1016/j.biopha.2018.10.131

26. Fu XJ, Fangm Y, Yao M. Antimicrobial photodynamic therapy for methycillin-resistant Sthapylococcus aureus infection. Biomed Res Int. (2013) 2013:9. doi: 10.1155/2013/159157

27. Pérez-Laguna V, García-Malinis AJ, Aspiroz C, Rezusta A, Gilaberte Y. Antimicrobial effects of photodynamic therapy. G Ital Dermatol Venereol. (2018) 153:833-46. doi: 10.23736/S0392-0488.18.06007-8

28. Moreno GA, Eng A, Alvarado A, Camps-Fresneda A. Photodynamic therapy. Med Cutan Iber Lat Am. (2007) 35:255-68. Available online at: https:// studylib.es/doc/5910112/terapia-fotodinamica

29. Aspiroz C, Sevil M, Toyas C, Gilaberte Y. Photodynamic Therapy with methylene blue for skin ulcers infected with Pseudomonas aeruginosa and Fusarium spp. Actas Dermosifiliogr. (2017) 108:45-8. doi: 10.1016/j.ad.2016.11.020

30. Morton CA, Szeimies RM, Basset-Séguin N, Calzavara-Pinton PG, Gilaberte Y, Haedersdal M, et al. European dermatology forum guidelines on topical photodynamic therapy. Part 2: emerging indications- field cancerization, photorejuvenation and inflammatory/infected dermatoses. J Eur Acad Dermatol Venereol. (2019) 34:17-29. doi: 10.1111/jdv.16044

31. Ogonowska P, Gilaberte Y, Barańska-Rybak W, Nakonieczna J. Colonization with Staphylococcus aureus in atopic dermatitis patients: attempts to reveal the unknown. Front Microbiol. (2021) 11:567090. doi: 10.3389/fmicb.2020. 567090

32. Sellera FP, Gargano RG, Pogliani FC. Photodynamic therapy: a review. Revista de Educaçao Continuada em Medicina Veterinaria e Zootecnia de CRMV-S12 P. (2014) 126-13. doi: 10.36440/recmvz.v12i1. 23097

33. Lambrechts SGA, Aalders MCG, Hasan T, Hamblin M. Photodynamic therapy for Staphylococcus aureus infected burn wounds in mice. Photochem Photobiol Sci. (2005) 4:503-9. doi: 10.1039/b502125a

34. Dai T, Tegos GP, Zhiyentayev T, Mylonakis E, Hamblin MR. Photodynamic therapy for methicillin-resistant Staphylococcus aureus infection in a mouse skin abrasion model. Lasers Surg Med. (2010) 42:38. doi: 10.1002/lsm. 20887
35. Almeida PP, Pereira IS, Rodrigues KS, Leal LS, Marques AS, Rosa LP, et al. Photodynamic therapy controls of Staphylococcus aureus intradermal infection in mice. Lasers Med Sci. (2017) 32:1337-42. doi: 10.1007/s10103-01 7-2247-1

36. De Melo WC, Avci P, de Oliveira MN, Gupta A, Vecchio D, Sadasivam $M$, et al. Photodynamic inactivation of biofilm: taking a lightly colored approach to stubborn infection. Expert Rev Ant Infect Ther. (2013) 11:669-93. doi: 10.1586/14787210.2013. 811861

37. Geralde MC, Leite IS, Inada NM, Salina ACG, Medeiros AI, Klueber W, et al. Pneumonia treatment by photodynamic therapy with extracorporeal illumination-an experimental model. Physiol Rep. (2017) 5:e13190. doi: 10.14814/phy2.13190

38. Pérez-Laguna V, Gilaberte Y, Millán-Lou MI, Agut M, Nonell S, Rezusta A, et al. A combination of photodynamic therapy and antimicrobial compounds to treat skin and mucosal infections: a systematic review. Photochem Photobiol Sci. (2019) 18:1020-9. doi: 10.1039/C8PP00534F

39. Pérez-Laguna V, García-Luque I, Ballesta S, Pérez-Artiaga L, Lampaya-Pérez V, Rezusta A, et al. Photodynamic therapy using methylene blue, combined or not with gentamicin, against Staphylococcus aureus and Pseudomonas aeruginosa. Photodiagnosis Photodyn Ther. (2020) 31:101810. doi: 10.1016/j.pdpdt.2020. 101810

40. Fila G, Kasimova K, Arenas Y, Nakonieczna J, Grinholc M, Bielawski PK, et al. Murine model imitating chronic wound infections for evaluations of antimicrobial photodynamic therapy efficacy. Front Microbiol. (2016) 7:1258. doi: $10.3389 /$ fmicb.2016.01258

41. Patra V, Wagner K, Arulampalam V, Wolf P. Skin microbioma modulates the effect of ultraviolet radiation on cellular response and immune function. IScience. (2019) 15:211-22. doi: 10.1016/j.isci.2019. 04.026

42. Hu X, Guo J, Zhao C, Jiang P, Maimai T, Yanyi L, et al. The gut microbiota contributes to the development of Staphylococcus aureus-induced mastitis in mice. ISME J. (2020) 14:1897-910. doi: 10.1038/s41396-02 0-0651-1

43. Ansell. DM, Campbell L, Thomason HA, Brass A, Hardman MJ. A statistical analysis of murine incisional and excisional acute wound models. Wound Rep Reg. (2014) 22:281-7. doi: 10.1111/wrr.12148

44. Niedre M, Yu CS, Patterson MS, Wilson BC. Singlet oxygen luminescence as an in vivo photodynamic therapy dose metric: validation in normal mouse skin with topical amino-levulinic acid. BJC. (2005) 92:298304. doi: 10.1038/sj.bjc.6602331

45. Dai T, Kharkwal GB, Tanaka M, Huang YY, Bil de Arce VJ, Hamblin MR. Animal models of external traumatic wound infections. Virulence. (2011) 2:296-315. doi: 10.4161/viru.2.4. 16840

46. Gilaberte Y, Serra-Guillén C, de las Heras E, Ruiz-Rodriguez $\mathrm{R}$, Fernández-Lorente $\mathrm{M}$, Benvenuto-Andrade $\mathrm{C}$, et al. Terapia fotodinámica en dermatología. Act Dermosifiliogr. (2006) 7:83102. doi: 10.1016/S0001-7310(06)73359-2

47. Abrha S, Bartholomaeus A, Tesfaye W, Thomas J. Impetigo animal models: a review of their feasibility and clinical utility for therapeutic appraisal of investigational drug candidates. Antibiotics. (2020) 9:694. doi: 10.3390/antibiotics9100694

48. Montagna W, Chase HB, Melaragno HP. The skin of hairless mice. 1. The formation of cysts and the distribution of lipids. J. Invest Dermatol. (1952) 19:83-94. doi: 10.1038/jid.1952.67

49. Topaloglu N, Güney M, Yuksel S, Gülsoy M. Antibacterial photodynamic therapy with 808-nm laser and indocyanine green on abrasion wound models. J Biomed Opt. (2015) 20:28003. doi: 10.1117/1.JBO.20.2. 028003

50. Erdur B, Ersoy G, Yilmaz O, Ozkutuk A, Sis B, Karcioglu O, et al. A comparison of the prophylactic uses of topical mupirocin and nitrofurazone in murine crush contaminated wounds. Am J Emerg Med. (2008) 26:13743. doi: 10.1016/j.ajem.2007.03.030

51. Ogunniyi AD, Kopecki Z, Hickey EE, Khazandi M, Peel E, Belov K, et al. Bioluminiscent murine models of bacterial and scald wound infections for antimicrobial efficacy testing. 
PLoS ONE. (2018) 13:e0200195. doi: 10.1371/journal.pone.0 200195

52. Guo Y, Ramos IR, Cho JS, Donegan NP, Cheung AL, Miller Y, et al. In vivo bioluminescence imaging to evaluate systemic and topical antibiotics against community-acquired methicillin-resistant Staphylococcus aureusInfected skin wounds in mice. Antimicrobial Agents Chem. (2013) 2:57 85563. doi: 10.1128/AAC.01003-12

53. Pérez-Laguna V, Pérez-Artiaga L, Lampaya-Pérez V, García-Luque I, Ballesta S, Nonell S, et al. Bactericidal effect of photodynamic therapy, alone or in combination with mupirocin or Linezolid, on Staphylococcus aureus. Front Microbiol. (2017) 8:1002. doi: 10.3389/fmicb. 2017.01002

54. Gilbert M. Topical $2 \%$ mupirocin versus $2 \%$ fusidic acid ointment in the treatment of primary and secondary skin infections. J Am Acad Dermatol. (1989) 20:1083-7. doi: 10.1016/S0190-9622(89)70137-7

55. Tazehjani L, Farahpour M, Hamishehkar H. Effectiveness of topical caraway essential oil loaded into nanostructured lipid carrier as a promising platform for the treatment of infected wound. Colloids Surf A: Physicochem Eng Aspects. (2021) 610:125748. doi: 10.1016/j.colsurfa.2020.125748

56. Farahpour MR, Pirkherzr E, Ashrafian A, Sonboli A. Accelerated healing by topical administration of Salvia officinalis essential oil on Pseudomonas aeruginosa and Staphylococcus aureus infected wound model. Biomed Pharmacother. (2020) 128:110120. doi: 10.1016/j.biopha.2020.110120

57. Wozniak A, Grinhold M. Combined antimicrobial activity of photodynamic inactivation and antimicrobials-state of the art. Front Microb. (2018) 9:930. doi: 10.3389/fmicb.2018.00930

58. Nesi-Reis V, LopesLeraNonose D, Sth., Oyama J, Silva-Lalucci MPP, Galhardo Dermachi I, et al. Contribution of photodynamic therapy in wound healing: a sistematic review. Photodiagnosis Photodyn Ther. (2018) 21:294305. doi: 10.1016/j.pdpdt.2017.12.015

59. Bairy KL, Pawan Kumar AV, Avinash MH, Chandra Shekar BR, Bhavya B, Satish Kumar MC. Comparative effect of calcium mupirocin and fluticasone on experimentally induced burn wound healing in rats. Int J App Biol Pharm Tech. (2011) 2:140-3. Available online at: https://eprints.manipal.edu/1753/

60. Chen L, Mirza R, Kwon Y, DiPietro LA, Koh TJ. The murine excisional wound model: Contraction revisited. Wound Repair Reg. (2015) 23:8747. doi: $10.1111 /$ wrr. 12338

61. Daemi A, Lotfi M, Farahpour MR, Oryan A, Ghayour SJ, Sonboli A. Topical application of Cinnamomum hydroethanolic extract improves wound healing by enhancing re-epithelialization and keratin biosynthesis in streptozotocin-induced diabetic mice. Pharm Biol. (2019) 57:799806. doi: 10.1080/13880209.2019.1687525

62. Seyed Ahmadi SG, Farahpour MR, Hamishehkar H. Topical application of Cinnamon verum essential oil accelerates infected wound healing process by increasing tissue antioxidant capacity and keratin biosynthesis. Kaohsiung $J$ Med Sci. (2019) 35:686-94. doi: 10.1002/kjm2.12120

63. Wong VW, Sorkin M, Glotzbach JP, Longaker MT, Gurtner GC. Surgical approaches to create murine models of human wound healing. J. Biomed Biotech. (2011) 2011:969618. doi: 10.1155/2011/969618

64. Jorge AE, Hamblin MR, Parizotto NA, Kurachi C, Vanderlei B. Photodynamic therapy improves the ultraviolet-irradiated hairless mice skin. NASA Astrophys Data Syst. (2014) 1. doi: 10.1117/12.2040297

65. Theunissen D, Seymour B, Forder M, Cox SG, Rode H. Measurements in wound healing with observations on the effects of topical agents on full thickness dermal incised wounds. Burns. (2016) 42:556-63. doi: 10.1016/j.burns.2015.09.014

66. Tiganescu A, Hupe M, Uchida YM, Mauro T, Elias PM, Holleran WM. Increased glucocorticoid activation during mouse skin wound healing. J. Endocrinol. (2014) 221:51-61. doi: 10.1530/JOE-13-0420

67. Zolfaghari P, Packer S, Singer M, Nair SP, Bennett J, Street C, et al. In vivo killing of Staphylococcus aureus using a light-activated antimicrobial agent. BMC. (2009) 9:27. doi: 10.1186/1471-2180-9-27

68. Altoé L, Alves RS, Sarandy MM, Morais-Santos M, Novaes RD, Gonçalves RV. Does antibiotic use accelerate o retard cutaneous repair? A systematic review in animal models. PLoS ONE. (2019) 14:e0223511. doi: 10.1371/journal.pone.0223511

69. Okür NU, Hokenek N, Okur ME, Ayla S, Yoltas A, Siafaka P, et al. An alternative approach to wound healing field; new composite film from natural polymers for mupirocin dermal delivery. Saudi Pharm J. (2019) 27:73852. doi: $10.1016 /$ j.jsps.2019.04.010

70. Sritharadol R, Nakpheng T, Heng OWS, Srichana T. Development of a topical mupirocin spray for antibacterial and wound-healing applications. Drug Dev Indust Pharm. (2017) 43:1715-28. doi: 10.1080/03639045.2017. 1339077

71. Golmohammadi T, Najar-Peerajeh S, Tohidi T, Moghadam T, Javal Hoseini SM. Synergistic antibacterial activity and wound healing properties of Selenium-Chitosan-Mupirocin Nanohibrid System: an in vivo study on rat diabetic Staphylococcus aureus wound infection model. Sci Rep. (2020) 10:2854. doi: 10.1038/s41598-020-59510-5

72. Vecchio D, Dai T, Huang L, Fantetti L, Roncucci G, Hamblin MR. Antimicrobial photodynamic therapy with RLP068 kills methicillinresistant Staphylococcus aureus and improves wound healing in a mouse model of infected skin abrasion. J Biophotonics. (2013) 6:733-42. doi: 10.1002/jbio.201200121

73. Morimoto K, Ozawa T, Awazu K, Ito N, Honda N, Matsumoto S, et al. Photodynamic Therapy using systemic administration of 5Aminolevulinic acid and $410 \mathrm{~nm}$ wavelength light emitting diode for methicillin-resistant Staphylococcus aureus infected ulcers in mice. PLoS ONE. (2014) 9:e105173. doi: 10.1371/journal.pone. 0105173

74. Pérez-Laguna V, Rezusta A, Ramos JJ, Ferrer LM, Gené J, Revillo MJ, et al. Daylight photodynamic therapy using methylene blue to treat sheep with dermatophytosis caused by Arthroderma vanbreuseghemii. Small Ruminant Res. (2017) 150:97-101. doi: 10.1016/j.smallrumres.2017. 03.011

75. Oyama J, Fernandes Herculano Ramos-Milaré ÁC, Lopes Lera-Nonose DSS, Nesi-Reis V, Galhardo Demarchi I, Alessi Aristides SM, et al. Photodynamic therapy in wound healing in vivo: a systematic review. Photodiagnosis Photodyn Ther. (2020) 30:101682. doi: 10.1016/j.pdpdt.2020. 101682

76. Valandro P, Massuda MB, Rusch E, Birgel DB, Pereira PPL, Sellera FP, et al. Antimicrobial photodynamic therapy can be an effective adjuvant for surgical wound healing in cattle. Photodiagnosis Photodyn Ther. (2021) 33:102168. doi: 10.1016/j.pdpdt.2020.102168

77. Sun Y, Ogara R, Xiao BH, Feng YX, Wu Y, Che LH, et al. Antimicrobial photodynamic therapy in skin wound healing: a systematic review of animal studies. IWJ. (2020) 17:285-99. doi: 10.1111/iwj.13269

78. Bunce C, Wheeler L, Reed G, Musser J, Barg N. Murine model of cutaneous infection with gram-positive cocci. Infect Immunity. (1992) 60:2636-40. doi: 10.1128/IAI.60.7.2636-2640.1992

79. Sun Y, Tosa M, Takada H, Ogara R. Photodynamic therapy delays cutaneous wound healing in mice. JNMS. (2020) 87:1107. doi: 10.1272/jnms.JNMS.2020_87-301

80. Jeong S, Lee J, Im BN, Park H, Na K. Combined photodynamic and antibiotic therapy for skin disorder via lipasa-sensitive liposomes with enhanced antimicrobial performance. Biomaterials. (2017) 141:24350. doi: 10.1016/j.biomaterials.2017.07.009

81. Yee R, Yuan Y, Shi W, Brayton C, Tarff A, Feng J, et al. Infection with persistent form of Staphylococcus aureus causes a persistent skin infection with more severe lesions in mice: failure to clear the infection by the current standard of care treatment. Discov. Med. (2019) 28:7-16.

82. Calabro K, Curtis A, Galarneau JR, Krucher T, Bigio IJ. Gender variations in the optical properties of skin in murine animal models. J Biomed Opt. (2011) 16:01108. doi: $10.1117 / 1.3525565$

Conflict of Interest: The authors declare that the research was conducted in the absence of any commercial or financial relationships that could be construed as a potential conflict of interest.

Copyright (๑ 2021 Pérez, Robres, Moreno, Bolea, Verde, Pérez-Laguna, Aspiroz, Gilaberte and Rezusta. This is an open-access article distributed under the terms of the Creative Commons Attribution License (CC BY). The use, distribution or reproduction in other forums is permitted, provided the original author(s) and the copyright owner(s) are credited and that the original publication in this journal is cited, in accordance with accepted academic practice. No use, distribution or reproduction is permitted which does not comply with these terms. 